\title{
Richard Long's Passage as Line: Measuring Toward the Horizon
}

\author{
Antonia Dapena-Tretter
}

In 1967, artist Richard Long became famous for completing his revolutionary A Line Made From Walking (Figure 1) —a simple black and white photograph of a straight line etched into the ground. Long's mark managed to underscore the perspectival space of the field as it receded into the distance, while it simultaneously functioned formally, akin to a Barnett Newman "zip" down the center of the canvas. This was not Long's first attempt to carve his mark onto the surface of the earth, but his earlier experimental work from 1966, Turf Circle, a large circle of grass sliced from its soil and reconstructed into a recessed position, was initially overshadowed by the sheer visual power of the line. Today, it is clear that both Turf Circle and A Line Made From Walking have become the basis for Long's life-long art practice. After decades of trekking in both straight and circular paths, the artist has progressively undertaken more ambitious walks, as is represented by a 1981 piece entitled A Line and Tracks in Bolivia: An Eleven Day Walk Crossing and Re-crossing a Lava Plain. Despite the increased scope, the premise remains the same, with Long etching a line into the land through his repeated movement back and forth over the surface of the earth. The performance of the walk, a ritual wandering, is only later documented through a photograph, marked map, or text work. Though the art object is created as a permanent remembrance of the walk, the traces are always ephemeral, sometimes drawn in the snow, or sometimes signified by upturned stones, and will disappear through the passing of time and exposure to the elements.

By making his own human contact with the earth the central focus of the artistic performance, Long marks his own presence and withdrawal from the site (Boetzkes 18). Because his physical body is almost never visible in the documenting photograph, the line alone reveals the artist's existence in the landscape but simultaneously 


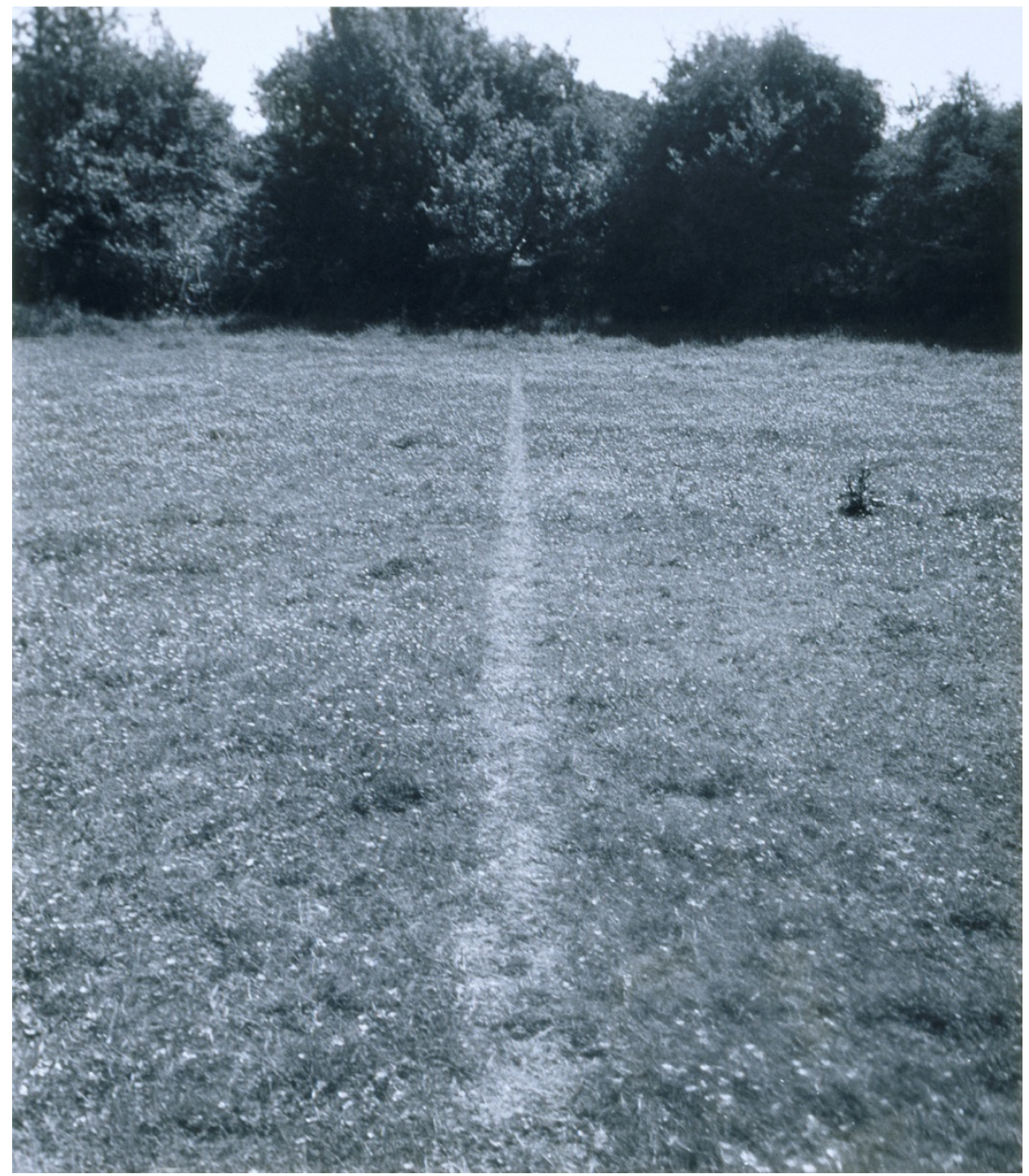

Figure 1 - A Line Made By Walking, 1967, Richard Long (born 1945). In the Tate collection. $(C$ Richard Long / SODRAC / Tate, London (2013).

announces his absence from the scene. This seemingly paradoxical insight extends the concept of passage beyond Long's traceable movements from point A to $\mathrm{B}$, with each coming and going gesturing toward the existential. In a 1982 artist's statement, Words After the Fact, published in conjunction with a solo exhibition at the Arnolfini Art Gallery in Bristol, Long announced to the world: "My work has become a simple metaphor of life." With this highly charged statement, the artist offered up his oeuvre for thoughtful reflection; his artworks are not to be appreciated exclusively on an aesthetic level, but rather with a certain ontological attention.

It is significant that Long's artistic breakthrough came during his time at St. Martin's College (1966-1968) as a student in the recently developed Advanced Course. This unique program offered a rather unconventional approach to traditional artistic techniques, and former instructor Peter Atkins recalled of his 
own curriculum that it was specifically engineered to expose young artists to a larger "philosophic, psychological and social context" (Heaven and Earth 38). It would seem that the atmosphere was intellectually inspiring for Long, and, in conversation with contemporary curator Clarrie Wallis, he fondly remembered the many hours spent poring over a copy of Bertrand Russell's 1945 History of Western Philosophy (38). It is reasonable to speculate then, that, given his keen interest in both path-making and philosophy, Long might have taken a special interest in the teachings of Martin Heidegger, a twentieth-century German philosopher who has written at least two texts devoted solely to the consideration of paths: Der Feldweg or The Pathway and Holzwege, literally translated as "wooded paths" but known to an English audience as Off the Beaten Track. Heidegger placed himself within a long trajectory of great thinkers-Hegel, Kant, Rousseau-who recognized the simple act of walking as a form of mediation (Roelstraete 11), asserting further that "[t]he pathway remains as close to the step of the thinker as to that of the farmer walking out to the mowing in early morning” (The Pathway 33). Thusly, Long, known world-wide for his lengthy path-making performances, also fits neatly into an established philosophic tradition of outdoor contemplation.

The following analysis seeks to put the artist in conversation with two great thinkers-Martin Heidegger and contemporary French philosopher Jean-Luc Nancy - with specific respect to issues of time, space, span, and the horizonLong's less obvious formal elements that have reoccurred with some frequency within the philosophic publications of both men. Hinting at the possible import of these concepts to his art, Long introduces visitors to his homepage with the following text-work:

In the nature of things:

Art about mobility, lightness and freedom.

Simple creative acts of walking and marking

about place, locality, time, distance and measurement.

Works using raw materials and my human scale

in the reality of landscapes.

With this poetic artist's statement, Long forgoes any lengthy discussion of his practice; instead, these lines serve as a condensed list of artistic principles centered around his measured movements through time in the landscape. Heidegger and Nancy clarify how these various ideas express themselves in Long's walking performance and allow the artist to explore, not just his own passage, but the relationship between one solitary path and those countless strands which make up the collective human journey. Ultimately, Long's lines and circles morph together on the landscape to reveal both a Heideggerian concept of life as passage and a more complicated physical manifestation of Nancy's theory of infinite finitude, an incalculable expanse of delineated lifespans. 


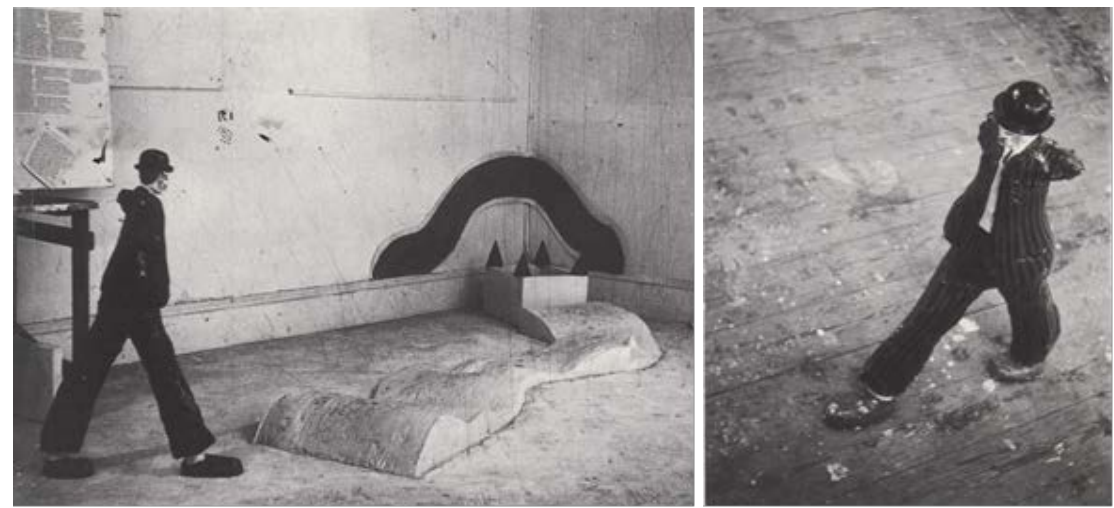

Figure 2 - Walking Man and Plaster Path (at the West of England College of Art, Bristol), 1965, Richard Long (born 1945). (C) Richard Long / SODRAC (2013).

\section{Lines and Circles as Opposing Symbols}

During an interview with critic Nick Stewart, Long said of his mature art, "my work is very simple...it is shapes and forms which are not my own, circles and lines belong to everyone, anyone can understand them" (Stewart 13). Even Long's textworks explore both shapes; Human Nature Walk (2011), for example, is composed of words arranged top to bottom in a circular pattern, as opposed to traditional lines of text. As universal symbols, lines and circles are deceivingly uncomplicated, but contrary to Long's assertion, it is critical to flesh out the significance behind both forms. The purpose of the line etched into the earth is not merely an artistic maneuver to visually divide space. It represents a more complicated attempt to display the artist's progression through both time and space as he moves across the landscape. Walking Man and Plaster Path (Figure 2), completed two years before Long's A Line Made By Walking, while arguably unsuccessful, offers insight into this symbolic use of the straight line. Long constructed a plaster sculpture of a manmost likely a self-portrait given the lanky legs-walking along a winding path. Hanging alongside the work, he posted a collection of texts exploring the relativity of time and motion. Here we can see Long's budding interest in space and time as expressed through passage. An early piece, and still somewhat traditional, the work failed to actually demonstrate the spatial-temporal reality of Long's lines. The documents making reference to time hung stagnantly on the wall behind the plaster man and his path, together but separate.

In Old Year New Year Walk, a much later text-work from the early 1990s, Long proves that he can successfully convey spatial-temporality through his specificallychosen parameters. The text describes a day in terms of both the number of hours experienced (twenty-four) and the number of miles covered (eighty). The twentyfour hour period selected was far from random, however. He set out on his journey during the remaining twelve hours of 1992 and reached his eightieth mile twelve hours into 1993. The walk represented for Long the end of the old year and the beginning of the new, framing the distance covered as a quantification of the time 


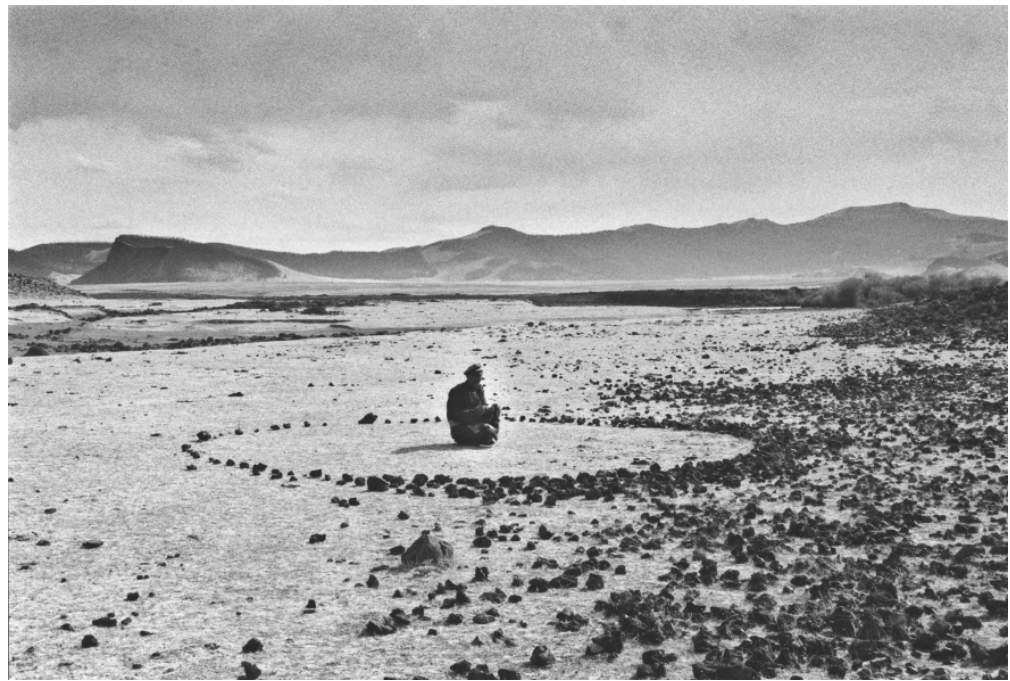

Figure 3 - Nomad Circle, Mongolia, 1996, Richard Long (born 1945). (c) Richard Long / SODRAC (2013).

passed. Like the ceremonial balls dropping in cities around the world, Long too celebrated the passing of time, but he did so through space.

If Long's lines demonstrate a defined, and therefore finite, exploration of spatialtemporality, as was overtly suggested by Walking Man and Plaster Path, what do we make of his circles with their distinguishing lack of beginning and end? The line reveals the artist's passage from one point to another, but walking in circles is rarely described in terms of a progression. The finitude inherent in the line, mathematically defined by its two ending points, contrasts with the never-ending circle. Like the sentiment afforded to a wedding ring, it has come to symbolize consistency, eternity, and other unchanging qualities.

Because something is everlasting, however, does not necessarily mean that it is still or stagnant. Consider, for instance, the infinite motion contained within the sun's orbital passage. In the case of Nomad Circle (Figure 3), the artist photographs a man sitting, stationary, inside the space of a carefully constructed circle of stones and pebbles. Given the title, it is safe to conclude that the individual is meant to represent a nomad, or Long's nomadic tendencies, but the character seems oddly planted inside the static shape. Perhaps the lack of movement in an individual defined by his preference for passage (a nomad acquires the designation because he continuously roams) suggests instead that it may be the circle that is truly nomadic, a dynamic shape equally capable of expressing motion.

In summation, it would appear that Long has chosen to problematize the circle as a symbol of inertia, demonstrating through Nomad Circle that it has the potential to express a passage not unlike that symbolized by the line. The differences between the two types of mobility rest instead on a question of duration: is the journey finite, defined by a particular starting and ending point, or without end, orbital, and infinite? In order to bridge the proverbial space between the finite and the infinite, one must meditate beyond this or that individual piece, acknowledging 
the continuity of Long's life-long art practice, its philosophical implications, and its context in nature.

\section{The Horizon: Where Ground Meets Sky}

The formal relationship between Long's mark and the surrounding landscape is undeniably important to the finished product- $\mathrm{a}$ line eloquently framed by a photograph's delineated borders. However, the rich theoretical implications of a human-made mark, whether it be the line or the circle, set purposefully within these natural elements has been little explored by the critical community. On a virtuallyunmarked frontier, Long has an unusual freedom to explore space, beyond the boundaries of the circle or the constructed distance indicated through the line. Less tangible lines and boundaries already exist in the landscape, the ultimate being that of the horizon, a word derived from the Greek horos, meaning "boundary, limit, frontier, border; land-mark” (Inwood 98). By avoiding urban landscapes with their complicated skylines, the artist is able to address with some exactitude his own artistic interactions with the otherwise unbroken expanse of land and sky. On the subject of human interventions with their environment is a short essay, Poetically Man Dwells, written by Martin Heidegger in response to a work by German Romantic poet Johann Christian Friedrich Hölderlin (1770-1843). In his analysis of the poem, Heidegger directs the reader to the true nature of dwelling, not dwelling within a building, but within the world around us. The reader learns quickly that we can only understand our dwelling on earth by situating ourselves within the enclosure that contains the earth, the ultimate dwelling, that which is delineated by the sky. We are to ponder our place in the universe by looking up toward the heavens and grappling with the unknowability of the godhead. Heidegger expands:

The godhead is the 'measure' with which man measures out his dwelling, his stay on the earth, beneath the sky...measure-taking gages the between, which brings the two, heaven and earth, to one another. (221)

In this short passage we find two distinct realms: the earth where humans dwell and the heavens where the godhead makes itself manifest. Through measure-taking, the mortal can explore the possible relationship between the two, gauging the space in between. While this might seem an impossible measure, the second part of the quotation tells us that this act allows us to bring the earth and the heavens together. This gesture describes the formation of a horizon, the precise point at which the earth meets the sky. Heidegger refers to many different horizons in his texts-Being and Time, The Basic Problems of Phenomenology, Contributions to Philosophy, Conversations on a Country Path about Thinking, among others-but generally the term is used to describe a sort of metaphorical vantage point from where meaning might be gathered. The horizon in this particular literary context signals a unique place where the mortal realm touches the immortal, and, so, 
measuring the "between" has the potential to offer a specific sort of insight into our own mortality.

Serving as a beacon, this horizon is ever-present in the background, luring the artist onward. His line stretches toward the unreachable boundary: "straight roads undulating to the horizon," as described by Long in his 1998 text-work A Walk Across Ireland. Even when the walker and his path are entirely fabricated, built from plaster and erected inside the space of a room, the artist positions his line toward the suggestion of a mountainous horizon, seen in Figure 2 on either side of the back corner. It is likely that the tall figure in the foreground has been purposefully exaggerated in order to create a sense of distance between the man and the horizon. It has been said that Long "can walk a path to the horizon, the beginning of the sky," (Fuchs 231) but while he forges a path in the direction of the horizon, it retreats as quickly as he approaches. Jean-Luc Nancy, ostensibly inspired by Heidegger's notion of the horizon, instead envisions a relationship defined by this inevitable spacing:

It is no longer a line that is drawn, or a line that will be drawn, which orients or gathers the meaning of a course of progress or navigation. It is the opening [la brèche] or distancing [le cartement] of horizon itself, and in the opening: us. We happen as the opening itself, the dangerous fault line of a rupture. (Being Singular Plural xii)

Nancy visualizes the spacing out of Heidegger's horizon, the material spreading and moving apart. It becomes a horizon without horizon. Via the deconstruction of the metaphysical horizon, the rigid boundaries that might define a horizon line are lost; there is only the space that remains. This view of the horizon is not empty, though; rather, it is within the infinite spacing of the horizon that the world and its inhabitants exist. In a later publication, Creation of the World, or, Globalization, Nancy expanded further on how such a space might in fact be full: "In truth, the 'open' isn't a yawning gap [une béance] but rather a mass, the massiveness of our bodies. Therefore it's only opened by being repeatedly excavated, dug up at its opening to the point of being clogged” (105). The stretch of horizon is brimming with life, contact between bodies that itself happens as spacing.

This concept clearly distinguishes Nancy's thoughts on horizon from the earlier philosopher, but despite Heidegger's preoccupation with a definite point of horizon, both scholars agree that our relationship to this important location shapes our everyday existence and capacity for ontological understanding. As life exists for Nancy within the gap, so too does Heidegger position us in accordance with the forming horizon: "Man dwells by spanning the "on the earth' and the 'beneath the sky.' This on and beneath belong together. Their interplay is the span that man traverses at every moment in so far as he is an earthly being” (Poetically Man Dwells 223). By tethering mankind to the ground, Heidegger stresses our mortality while simultaneously challenging us to span not just the landscape, but the interplay between the earth and sky—-the horizon. Long clearly accepts the challenge. 


\section{The Horizon: Where Ground Meets Sky}

Given that the word "span" is used twice in this essential quotation, the specifics of the word warrant inspection. Heidegger's texts were all written auf Deutsch, and as such, it is necessary to note that the German meaning of the word carries the same connotations as the English. Span is the "distance from the tip of the thumb to the tip of the little finger, or sometimes to the tip of the forefinger, when the hand is fully extended; the space equivalent to this taken as a measure of length, averaging nine inches," but it also implies a short period of time, as in "the duration of human life; the (short) time during which a person lives" (OED). It seems that spanning is far from a precise form of measurement, but instead functions loosely through human contact. Our bodies become the tool with which to gauge a span; as Long suggests in the introductory text-work, our stride can serve as a sort of "human scale." It now seems safe to exclude measurement in the sense of mathematical calculations, and Heidegger confirms this suspicion when he writes: "Thus it might be that our unpoetic dwelling, its incapacity to take measure, derives from a curious excess of frantic measuring and calculating” (Poetically Man Dwells 228). The most authentic act of measuring must be seen in terms of spanning, a gauging of difference through human contact and in terms of our finite abilities. We are to measure with our hands, or, in the case of Long's practice, our feet, not with a measuring tape, and through our calculations we are to make sense of the interplay between the earth and the sky, or more abstractly, the mortal and immortal realms, designated in terms of a lifespan.

Because Heidegger repeatedly defines the sky using the metaphor of the godhead, the reader must question what happens if Heidegger's godhead is shown to be absent as Nancy asserts in his Of Divine Places. An answer to this puzzling question can be found in a chapter of Nancy's The Sense of the World, appropriately titled Spanne (the German equivalent of the English span). For Nancy, a Frenchman, to purposefully make reference to Heidegger's mother tongue within the context of a discussion of space and span, suggests that he was familiar with Heidegger's use of the word as taken from Poetically Man Dwells. Here, however, we recall that Heidegger had performed a close-reading of a poem by Hölderlin. The philosopher, asserting in a 1966 interview with Der Spiegel that this poet was particularly deserving of further study, noted Hölderlin's apparently praiseworthy attention to a god figure:

I consider Hölderlin not [just] one poet among others whose work the historians of literature may take as a theme [for study]. For me, Hölderlin is the poet who points into the future, who waits for a god, and who consequently, should not remain merely an object of research according to the canons of literary history. (Heidegger translated by Richardson 61-62)

Nancy offers a parallel way of making the point, allowing a metaphor of separation to replace the language of divinity: "If it is no longer God who is eternity, it is the 
spacing of the present of time, its separation and excitation: Spanne, Spannweite" (Sense of the World 66). In selecting time and space to replace the eternal figure of the godhead, Nancy describes an equally infinite force. We are now challenged to look at the spacing of the passing of time-itself as incommensurable as Heidegger's notion of the godhead-and both contemplate and traverse its span in order to create a place of understanding — a Heideggerian horizon.

Attention to Heidegger's masterpiece Being and Time enables the reader to better understand the precise nature of the understanding to be found at this horizon:

If temporality constitutes the meaning of the being of the human Dasein, and if understanding of being belongs to the constitution of the Dasein's being, then this understanding of being, too, must be possible only on the basis of temporality. Time is the horizon from which something like being becomes at all intelligible. (Being and Time 16-17)

It would appear that Heidegger and Nancy ultimately agree: as temporal beings, we, like a line, are defined by our beginning and end, and it is through a mediation on our status as temporal beings that we might grasp ontological clarity.

Nancy's emphasis on spatial-temporality in lieu of Heidegger/Hölderlin's religious sense of the immortal godhead surprisingly changes very little-the reason being, perhaps, that early humans who attempted to understand time looked upwards to the heavens. Heidegger focusses on the heavenly body yet again, but this time to investigate the longstanding linkages between the sky and the measuring of time: "This dating of things in terms of the heavenly body which sheds forth light and warmth, and in terms of its distinctive 'places' in the sky, is a way of assigning time" (Being and Time 466). Time is not an arbitrary figure but a reflection of the sun's constant motion in the sky from sunrise to sunset. It has become a tool to determine morning, afternoon, evening, and when the sun has disappeared, night. The sun's "distinctive places in the sky" are also a direct reflection of the Earth's position as it orbits the sun, not coincidentally measured by Long in his text-work Engadine Walk (2004). The artist informs his viewer that "the Earth travels 22,260,000 miles in its orbit," but in the following line juxtaposes this precision with an image of the indefinite infinity of the universe: "Countless stars [/] the infinity of space." As Long marvels at the earth's yearly journey, a 365-day trip around the sun, Nancy reminds us that any journey can be used to explore the spacing of the present of time, and consequently human ontology.

Concentrating on time's spatial component, Nancy concludes Spanne by listing a number of timespans as delimited by two points of contact: "From the cup to the lips, from the Tarpeian Rock to the Capitol, from Charybdis to Scylla, from one border to the other, from one wall to the other, from one lip to the other, from you to me, from one time to the other" (Sense of the World 67). Each of these spans represents a journey, perhaps as slight as from one pair of lips to another, perhaps as grand as from one border to another, but in each instance, there is a defined passage 
of time represented between the two points as space. The visual representation of time between points, or passage itself, has become Long's chosen medium, and his works are differentiated from each other by their varying spatial-temporal ratios. Performing a rather immense journey in A Thousand Miles, A Thousand Hours, the artist covers such a large geographic area that the space between the two selected points "becomes more and more an accumulation of time, of moments, hours, days, nights, weeks... Slowly the work begins to equal his life” (Fuchs 103). It is noteworthy that Long documents this walk through a simple line drawing of the path, not a straight line or a circle, but a series of straight lines joined with corners to form an angular spiral. The drawn shape exhibits bumps where Long may have strayed from his path to go around obstacles but is otherwise a neatlyrendered visual demonstration of what the artist described below the work as a "clockwise walk in England Summer 1974." Both Long and his line wind through the landscape like the hands of a clock. Unlike the artist's assertion that his work is a "simple metaphor of life," with the extended passage of time, the allegorical has disappeared, leaving in its place, Long's path as life.

\section{Birth, Death, and Co-Existence}

When Heidegger passed away in 1976, a speech at his funeral, which the philosopher had previously approved, informed the listeners in the first line, "Martin Heidegger's path has come to an end" (Welte 73). Shortly into the speech, eulogist, Bernhard Welte, described Heidegger's life: “He traveled his path without ceasing. There were bends and turns along it, certainly there were stretches where he went astray" (73). Long expresses the same tendency in the last line of a 2001 text-work: "The walk as a true path / Some false moves." It is likely, considering the title, Heaven and Earth, that the true path is one that goes between the two realms-a trajectory defining Long's ongoing journey from birth to death. In Being Singular Plural, Nancy states definitively: "Birth and death, sharing and co-existence, belong to the infinite" (188). A singular human life is finite, but existence is always a co-existence; in the plurality of finite experiences, we find the infinite. With this concept surfaces a new way of understanding Long's line. As art, each line has an articulated end, but Long will begin a new line elsewhere on another occasion. Nancy says that "[t]he whole problem, if there is a problem, is of knowing if the execution, the finish, is finite or infinite” (Being Singular Plural 118). Our particular conundrum is whether the line terminates when Long reaches his endpoint. The answer is not obvious, but a clue surfaces midway through a text-work from 1995 entitled Dartmoor Time: "Holding a butterfly with a lifespan of one month / Climbing over granite 350 million years old on Great Mis Tor / Thinking of a future walk / Eight hours of moonlight.” Long compares the minute lifespan of an insect to the perpetuity of geologic time, before contemplating his own walk and corresponding line. He specifically ends the work by quantifying the total number of moonlit hours spent walking but simultaneously reminds his viewers that he is far from done. He is already thinking of future walks, revealing the constructed nature of the line's supposed finitude. Thus there is an imagined dotted line that connects 
the gaps between Long's many lines, envisioning the larger path that represents the totality of his existence- - the "true path." With Long still etching his way across the landscape, the sum total of his lines has not yet proven itself to be finite, but even after the artist's inevitable passing, other lines will form as humanity continues to mark its collective passage through time.

Suggesting a curiosity about the larger human network, Long roots his line in a broader view of human existence through his purposeful engagement with past and
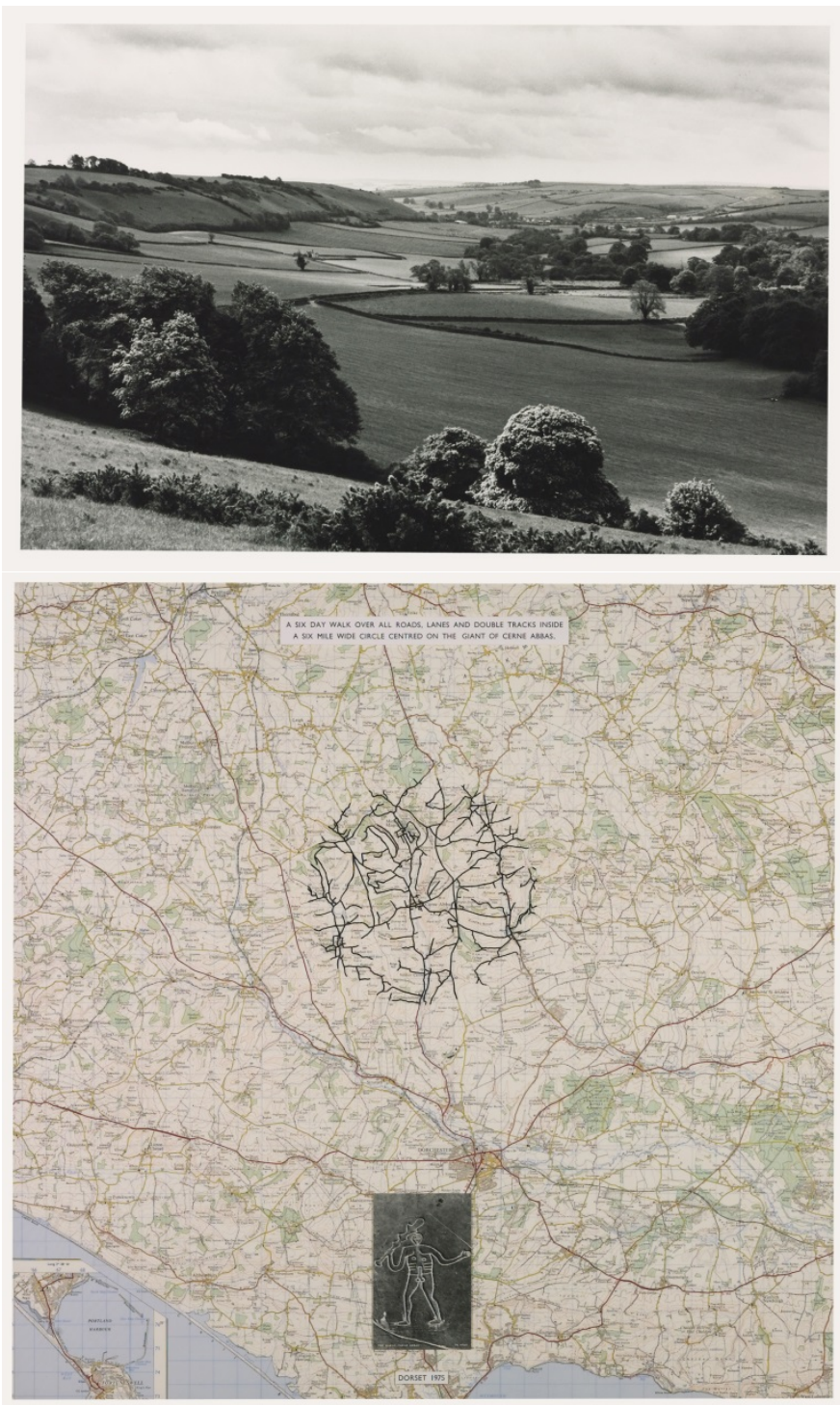

Figure 4 - Cerne Abbas Walk, 1975, Richard Long (born 1945). In the Tate collection. (C) Richard Long / SODRAC / Tate, London (2013). 
future monuments, such as those described in his text-work from 2008, Megalithic to Subatomic. Although very short, the text-work lists the crucial information necessary to decipher the piece: the beginning and end points, the miles covered, and the time it took for the artist to walk the path. Long begins his trip in Carnac, most known for its configurations of stones carefully arranged by pre-celtic peoples during the Neolithic period. By referencing the Carnac stones, Long seems to portray his art-making practices as stemming from a long tradition of human stone arranging. Of equal importance, though, is the end location; Long crosses France and enters Switzerland in order to arrive at CERN, otherwise known as the European Organization for Nuclear Research. In many ways, this institution is the birthplace of technologies yet to come. Long's line connects the past to the future, but both points are still firmly lodged within human history.

While Megalithic to Subatomic is a fairly recent text-work, decades earlier Long had already exposed an obvious interest in tracing his path back in time, relating his practice to peoples and places of particular relevance beyond his own lifespan. By doing so, the artist demonstrates Heidegger's notion of time as an infinite stream of moments, or, in the philosopher's own words, time as "endless on both sides" (Being and Time 475). Long's 1975 Cerne Abbas Walk (Figure 4), an artwork inspired by a large-scale prehistoric drawing of a giant on the earth's surface, is a case in point. Named the Cerne Abbas long ago by the local community of Dorset, England, the etched figure only exists today because the outline is continually refreshed. If ignored, it, like Long's mark, would have returned to the earth over a thousand years ago. Because the giant's pose is suggestive of walking-his legs spread open with both feet pointed forward-it has additional relevance to Long's artistic practice. For Cerne Abbas Walk, the artist traversed an immense circle around the figure and later superimposed the shape on a map. He then photographed both the landscape and the figure, adhering them to the front of the map-work. As evidence of the unique nature of the work, Long labeled an accompanying photographic piece: "His eyes watch over a country mile. The giant walks on the hill, one step, for ever." The combination of assorted artworks - the circular walking performance, the various photographs, the labeled map, and the final poetic stanza-together portray something new. As Long dreams of a giant whose step would last forever, he is only able to offer in comparison a small, finite human step, but the giant's immeasurable stride reinforces Long's interest in infinity. Because the Cerne Abbas giant has allowed Long to conceive of a walking piece that never ends, it joins together the finite line with the eternity expressed by the circle. When considering Long's many paths in terms of the never-ending stream of existences that have taken place and will take place, his already lengthy portfolio extends far beyond the quantifiable. The represented points of origin and ending transform into mere points, perhaps those of the suggestive ellipses...

\section{Conclusion}

Approaching an investigation of Richard Long's lines and circles through a philosophical lens has brought to light the complexity of the artist's practice. Long's 
lines illustrate the Heideggerian notion of life as passage, a Dasein stretched out between the moment of birth and death, with the importance remaining not at either end of the delineated span, but rather, on the journey itself, the way in which man should dwell during his brief sojourn. In Poetically Man Dwells, Heidegger instructs his reader to "span," a verb choice revealing, above all, the author's noted preference for a contemplative as opposed to calculative lifestyle. By considering the many nuances of the word-in terms of distance, imprecise measurement, and human finitude_Long's assertion that his art is "a simple metaphor of life” seems less of an abstraction, now grounded firmly in the artist's human contact with the earth. As Heidegger warns against frantic calculations, Long makes his mark methodically, scratching at the ground, expressing his passage against the eternity of space and time. As he spans the in-between, measuring time with his "human scale," he engages in a quest for an ontological understanding of mankind's existence in relation to the eternal forces which will one day wipe away his artworks. While he may count the number of hours it took to reach a particular mountain peak, the artist differentiates this method of measurement from potentially frenzied calculations by stressing instead the importance of his own foot, tallying distance in terms of a personal stride, his lived experience in the landscape. By choosing a relatively uninhabited outdoor setting for each performance, Long is able to situate his artwork against the horizon, thereby underscoring the inevitable spacing between man and this point of ultimate understanding, while also revealing the passing of time demonstrated by the sun's changing position in the sky.

Were it not for the endless nature of the circle, Long's audience would be at risk of over-emphasizing the finite attributes of the line. The line and the circle, while initially suggesting opposing conceptions - the finite versus the infinite-come together with succinct precision in the theoretical work of Nancy, revealing that the infinite might in fact be composed of the never-ending finite. With works like Megalithic to Subatomic and Cerne Abbas Walk, Long's path stretches beyond his own lifespan to encompass the considerably larger span of human history, allowing the artist to explore both his own mortality and its place within the infinite finitude of humanity. When turned into an art object-photograph, text-work, map-work, et cetera- to be displayed in a gallery setting the effect is not always convincing. The issue may be that the work has been removed from its original context, on the earth and beneath the sky. It is here that Long's works are truly expressive of man's ability to poetically dwell, spanning the landscape as it expands toward the distant horizon.

\section{Antonia Dapena-Tretter}

Antonia Dapena-Tretter is an emerging art historian and museum professional who received her Master's in Art History from the University of Toronto. She is broadly interested in modern and contemporary art, with research interests that range from Postwar German art to British Modernism. She has a particular passion for North American Colorfield paintings, fostered during her time living in Washington, D.C. and her involvement as a research assistant on the Jack Bush Catalogue 
Raisonné Project-a comprehensive publication to include over 1,700 artworks with corresponding dimensions, media, provenance, and exhibition history. Antonia returned to Washington in the summer of 2013 to serve as Head of Education at the Kreeger Museum, training docents and managing all educational programming. Antonia's attraction to museum work-initiated during her time at Dickinson College_-stems mainly from a deep appreciation for scholarship born out of a close interaction with art objects.

\section{Works Cited}

Boetzkes, Amanda. The Ethics of Earth Art. Minneapolis: University of Minnesota Press, 2010. Print.

Fuchs, R.H. Richard Long. Solomon R. Guggenheim Museum: New York, Thames \& Hudson, 1986.

Heidegger, Martin. Being and Time. 1st English ed. London: SCM, 1962. Print.

_. “Nur noch ein Gott kann uns retten,” Der Spiegel 30 (Mai, 1976): 193-219. Trans. by W. Richardson as “Only a God Can Save Us” in Heidegger: The Man and the Thinker (1981), ed. T. Sheehan. 45-67. Print.

—. "The Pathway.” Listening Journal of Religion and Culture 8.1, 2, 3 (1973): 3339. Print.

-. "Poetically Man Dwells" in Poetry, Language, Thought. New York: Perennial Classics, 2001. 211-29. Print.

Inwood, M. J. A Heidegger Dictionary. Malden, Mass.: Blackwell Publishers, 1999. Print.

Long, Richard. Artist's Professional Homepage. <www.RichardLong.org>

Nancy, Jean-Luc. Being Singular Plural. Stanford, CA: Stanford University Press, 2000. Print.

- The Creation of the World Or Globalization. Albany: State University of New York Press, 2007. Print.

- The Sense of the World. Minneapolis: University of Minnesota Press, 1997. Print.

Oxford English Dictionary Online. [S.l.] Oxford University Press: Oxford University Press. Web.

Richard Long: Heaven and Earth. Eds. Clarrie Wallis and Tate Britain (Gallery). New York: Distributed in the United States and Canada, 2009.

Roelstraete, Dieter. Richard Long: A Line made by Walking. London: After-all Books, 2010. Print.

Stewart, Nick. "Richard Long: Lines of Thought / A Conversation with Nick Stewart.” Circa 19 (1984): 8-13. Print.

Welte, Bernhard. "Seeking and Finding: The Speech at Heidegger's Burial," Listening, XII, 3 (Fall 1997): 1. Reprinted in Heidegger, the Man and the Thinker, 1981. 73-75. Print. 
Iowa Journal of Cultural Studies 15 (Spring 2014)

Copyright (C) 2014 by The University of Iowa 